\title{
Low Body Mass Index Is an Independent Prognostic Factor in Patients With Non-Small Cell Lung Cancer Treated With Epidermal Growth Factor Receptor Tyrosine Kinase Inhibitor
}

\author{
Seigo Minami ${ }^{\mathrm{a}}$ b, c, Shouichi Ihara ${ }^{\mathrm{a}}$, Kanako Nishimatsu ${ }^{\mathrm{a}}$, Kiyoshi Komuta ${ }^{\mathrm{b}}$
}

\begin{abstract}
Background: Sarcopenia and obesity have been suspected as factors associated with efficacy of treatment and prognosis in various malignancies. This study aimed to investigate the association of pretreatment sarcopenia and visceral obesity with efficacy and prognosis of first- and second-generation epidermal growth factor receptor (EGFR) tyrosine kinase inhibitor (TKI) for patients with non-small cell lung cancer (NSCLC) and positive EGFR mutation.
\end{abstract}

Methods: We retrospectively collected 167 NSCLC patients with mutant EGFR who had started EGFR-TKI monotherapy between October 2007 and August 2018 at our hospital. We classified 167 patients into two groups, according to the definition of underweight based on the World Health Organization (WHO) body mass index (BMI) classification and the Japanese sex-specific cut-off values of the following computed tomography (CT) images-assessed markers of pretreatment sarcopenia or visceral obesity, such as psoas muscle index (PMI), intramuscular adipose tissue content (IMAC) and visceral-to-subcutaneous fat ratio (VSR) at lumbar vertebra L3 level. We compared overall survival (OS) and progression-free survival (PFS) of two groups by Kaplan-Meier curves and log-rank tests. Using multivariate Cox proportional hazard analyses adjusted by age, neutrophil-to-lymphocyte ratio, performance status, EGFR mutation types and EGFR-TKI lines, and extra-pulmonary metastases or three or more than 3 metastatic sites, we searched independent prognostic factors of OS and PFS of EGFR-TKI therapy.

Results: The OS (median 26.0 vs. 32.3 months, $\mathrm{P}=0.02$ ) and PFS (9.1 vs. 14.8 months, $\mathrm{P}=0.03$ ) of patients with $\mathrm{BMI}<18.5$ were significantly shorter than those of patients with $\mathrm{BMI} \geq 18.5$. However, there was no significant difference in OS and PFS according to PMI,

Manuscript submitted November 16, 2019, accepted December 2, 2019

aDepartment of Respiratory Medicine, Osaka Police Hospital, 10-31 Kitayama-cho, Tennoji-ku, Osaka 543-0035, Japan

bDepartment of Respiratory Medicine, Daini Osaka Police Hospital, 2-6-40 Karasuga-tuji, Tennoji-ku, Osaka 543-8922, Japan

${ }^{\mathrm{c} C}$ Corresponding Author: Seigo Minami, Department of Respiratory Medicine, Osaka Police Hospital, 10-31 Kitayama-cho, Tennoji-ku, Osaka-City, Osaka 543-0035, Japan. Email: seigominami@oph.gr.jp

doi: https://doi.org/10.14740/wjon1244
IMAC and VSR. The multivariate analyses detected only BMI $<18.5$ as an unfavorable prognostic factor of shorter OS (hazard ratio (HR) $1.70,95 \%$ confidence interval $(\mathrm{CI}) 1.03-2.81, \mathrm{P}=0.04)$ and $\mathrm{PFS}(\mathrm{HR}$ $1.72,95 \%$ CI $1.11-2.67, \mathrm{P}=0.02)$.

Conclusions: Pretreatment underweight was a significant prognostic factor of poor PFS and OS of EGFR-TKI therapy. However, neither pretreatment sarcopenia nor visceral obesity was associated with prognosis of EGFR-TKI. Underweight may be a surrogate for advanced disease burden.

Keywords: Non-small cell lung cancer; Body mass index; Psoas muscle index; Intramuscular adipose tissue content; Visceral-tosubcutaneous fat ratio; Epidermal growth factor mutation; Tyrosine kinase inhibitor; Sarcopenia

\section{Introduction}

Non-small cell lung cancer (NSCLC) is categorized into several subsets according to active driver mutations. Among many driver mutations, epidermal growth factor receptor (EGFR) is the most important in terms of its frequency, long history, abundant evidences, and clinically available molecular-targeted drugs of tyrosine kinase inhibitors (TKIs). Reviewing many historic trials that have demonstrated better response, longer survival benefit and milder toxicity, EGFR-TKIs should be prioritized over conventional cytotoxic chemotherapy for patients with positive EGFR mutation. The median progression-free survival time of the first- and second-generation EGFR-TKIs was approximately 1 year. However, some patients unfortunately experienced early tumor progression.

Body mass index (BMI) is easily calculated only by body weight $(\mathrm{kg})$ divided by square height $\left(\mathrm{m}^{2}\right)$. It differentiates each person as underweight, normal weight, overweight or obese. Being underweight $\left(\mathrm{BMI}<18.5 \mathrm{~kg} / \mathrm{m}^{2}\right)$ at the time of diagnosis of advanced NSCLC has been reported to be associated with poor outcomes $[1,2]$. However, BMI cannot differentiate fat and muscle mass. There are sometimes considerable differences between body composition and BMI. Thus, BMI is not always a reliable parameter of nutritional status [3]. On 
the other hand, visceral adiposity has recently been suggested as a better predictor of poor outcomes in colorectal carcinoma than general obesity measured by BMI $[4,5]$. Computed tomography (CT) scan has been used to measure visceral fat area (VFA) and subcutaneous fat area (SFA), and the ratio of VFA/SFA (VSR) as indicators of visceral obesity. In various solid malignancies, it has been suggested that visceral obesity is associated with worse outcomes [6-10]. However, to our knowledge, there is no study evaluating visceral obesity as a prognostic factor in lung cancer.

Sarcopenia is defined by low muscle strength, low muscle quantity or quality, and low physical performance according to the European Working Group on Sarcopenia in Older People 2 (EWGSOP2) [11]. Although sarcopenia is common among elderly, it can occur earlier in life due to various causes. Sarcopenia has been recognized as a poor prognosis indicator in patients with various malignancies [12]. Using CT crosssections, image analysis of skeletal muscle areas has recently become standard. Among various CT-based muscle indexes, psoas muscle index (PMI) and intramuscular adipose tissue content (IMAC) have been widely used to assess skeletal muscle quantity and quality, respectively. An Italian retrospective study of 33 patients failed to detect sarcopenia as a significant prognostic factor of molecular-targeted therapy of EGFR-TKI, gefitinib, for advanced NSCLC [13].

The aim of this study was to investigate BMI, PMI, IMAC and VSR with prognosis of first- and second-generation EGFR-TKIs in patients with mutant EGFR.

\section{Patients and Methods}

\section{Patients and study design}

This was a single-institutional and retrospective study. The inclusion criteria were as follows: 1) Pathological diagnosis of NSCLC; 2) Patients with active EGFR mutation confirmed by the peptide nucleic acid-locked nucleic acid PCR clamp method or EGFR gene mutation analysis COBAS version 2, which had been examined by LSI Medience Cooperation (Tokyo, Japan); 3) Patients who had initiated gefitinib, erlotinib or afatinib between October 2007 and August 2018 at our hospital; 4) CT scan covering L3 level within 3 months and peripheral venous blood test within 2 weeks prior to the start of EGFR-TKI. We collected the following pretreatment backgrounds and treatment results: sex, age, height, body weight, smoking history, cancer histopathology, EGFR mutation status, Eastern Cooperative Oncology Group (ECOG) performance status (PS), number of metastatic sites, extra-pulmonary metastases, numbers of neutrophils and lymphocytes, EGFR-TKI regimen, treatment response according to the Response Evaluation Criteria in Solid Tumors (RECIST) version 1.1 [14], progression-free survival (PFS) and overall survival (OS). PFS and OS were the intervals between the first day of EGFR-TKI and progressive disease (PD) or death, and death due to any causes, respectively. Response rate (RR) and disease control rate $(\mathrm{DCR})$ were the rates of complete response $(\mathrm{CR})+$ partial response $(\mathrm{PR})$, and $\mathrm{CR}+\mathrm{PR}+$ stable disease $(\mathrm{SD})$ in all pa- tients, respectively. The neutrophil-to-lymphocyte ratio (NLR) was calculated by dividing the number of neutrophils by the number of lymphocytes. The data were cut-off on August 31, 2019. This study observed the Declaration of Helsinki. The Osaka Police Hospital Ethics Committee approved our study, and permitted waiver of the written informed consents because of the retrospective and anonymous study design.

\section{CT image analysis}

We used SYNAPSE VINCENT software (Fujifilm Medical, Tokyo, Japan), enhanced or plain cross-sectional CT images taken for the practical purpose of diagnosing, staging or follow-up assessment, and CT attenuation values at the level of transverse process of lumbar vertebra L3. The bilateral psoas muscle area, VFA and SFA were automatically identified and then manually corrected. The multifidus muscles area was manually traced. PMI $\left(\mathrm{cm}^{2} / \mathrm{m}^{2}\right)$, IMAC and VSR were calculated by dividing psoas muscle area $\left(\mathrm{cm}^{2}\right)$ by the square of the patient's height $\left(\mathrm{m}^{2}\right)$ [15], the CT attenuation value (Hounsfield Unit, HU) of the bilateral multifidus muscles by that (HU) of four circles with the diameter of $6 \mathrm{~mm}$ on subcutaneous fat away from major vessels [16], and VFA by SFA, respectively. Representative CT images are shown in Figure 1. Reviewing the previous Japanese studies, as the sex-specific cut-off points for PMI, IMAC and VSR, we pre-defined $6.36 \mathrm{~cm}^{2} / \mathrm{m}^{2}$ for men and $3.92 \mathrm{~cm}^{2} /$ $\mathrm{m}^{2}$ for women [15], and -0.358 for men and -0.229 for women [17], and 1.33 for men and 0.93 for women [18], respectively.

\section{Data analysis}

Continuous data, categorical data and survival time were shown by median with interquartile range (IQR), frequencies and median time (months) with 95\% confidence intervals (CIs), and then were compared by the Mann-Whitney U test, Fisher exact test, and Kaplan-Meier method with log-rank test, respectively. Correlations between BMI, PMI, IMAC and VSR were analyzed using Spearman's rank correlation coefficient $\left(r_{s}\right)$. The multivariate Cox proportional hazards analyses adjusted BMI, PMI, IMAC and VSR by the following six factors: age ( $<75$ vs. $\geq 75$ years), NLR $(<5$ vs. $\geq 5)$, ECOGPS (0 - 1 vs. 2 - 4), EGFR mutation status (exon 19 deletion vs. others), EGFR-TKI regimen line (first vs. second or later line) and extra-pulmonary metastases (yes vs. no) or three or more than three metastatic sites. Thereafter, the results were described as hazard ratios (HRs) with 95\% CI. P-value $<0.05$ was considered to indicate a statistically significant difference. Using EZR (Saitama Medical Center, Jichi Medical University, Saitama, Japan) [19], which is a graphical user interface for R (The R Foundation for Statistical Computing, Vienna, Austria), we performed all statistical analyses.

\section{Results}

We collected 167 NSCLC patients with mutant EGFR treated 
Case 1
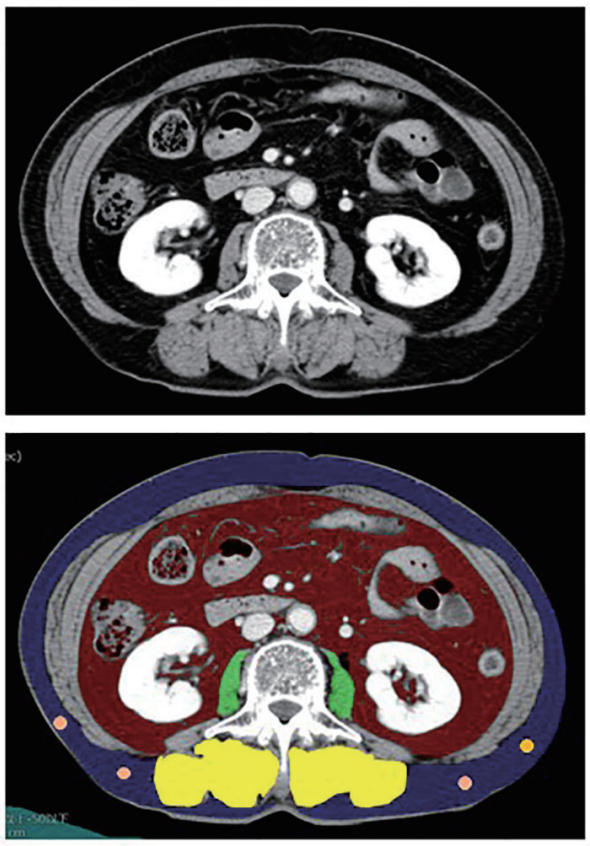

Case 2
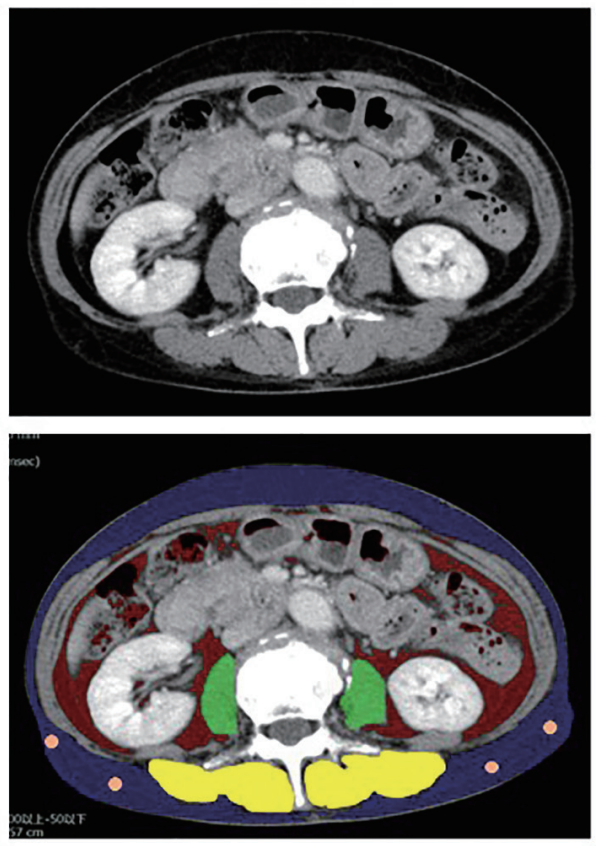

\begin{tabular}{lcl}
\hline $68 \mathrm{~F}$ & Age / Sex & $66 \mathrm{~F}$ \\
23.4 & $\mathrm{BMI}$ & 23.1 \\
2.38 & $\mathrm{PMI}$ & 4.76 \\
-0.51 & IMAC & -0.82 \\
1.38 & VSR & 0.26 \\
\hline
\end{tabular}

Figure 1. Representative cross-sectional CT images obtained at the third lumber vertebra. Two female patients had similar $\mathrm{BMI}$ and age, but different PMI, IMAC and VSR. The areas of bilateral psoas muscles, visceral fat, subcutaneous fat, multifidus muscle and subcutaneous four small circles were identified by green, red, blue, yellow and orange. CT: computed tomography; BMI: body mass index; PMI: psoas muscle index; IMAC: intramuscular adipose tissue content; VSR: visceral-to-subcutaneous adipose tissue area ratio.

with EGFR-TKI. We divided them into two groups according to the cut-off points of BMI, PMI, IMAC and VSR. Until the cut-off date, we experienced 101 deaths, 33 survivals, 33 lost to follow-up, 133 PD during or after gefitinib, erlotinib or afatinib, and 24 introduction of osimertinib after gefitinib, erlotinib or afatinib. The reasons of discontinuation of EGFRTKIs were PD in 101 patients, adverse effects in 20, deteriorated general conditions in 12 , deteriorated other diseases in seven, patient's refusal in five, and transfer to other medical or nursing institutions in four. Eighteen patients still continued EGFR-TKIs. Nine patients changed an EGFR-TKI to another TKI because of adverse effects: from gefitinib to erlotinib in six patients, from erlotinib to gefitinib in two, and from afatinib to gefitinib in one. Except for one squamous cell carcinoma, one adenosquamous cell carcinoma and one non-specific NSCLC, histology was all adenocarcinoma. There were 33 underweight (BMI < 18.5), 104 normal weight $(18.5 \leq$ BMI $<25.0), 24$ overweight $(25.0 \leq \mathrm{BMI}<30.0)$ and six obese $(\mathrm{BMI}>30.0)$ patients.

Except for between PMI and IMAC $\left(r_{s}=0.005, P=0.95\right)$, there were statistically significant correlations between BMI and PMI $\left(\mathrm{r}_{\mathrm{s}}=0.37, \mathrm{P}<0.01\right), \mathrm{BMI}$ and IMAC $\left(\mathrm{r}_{\mathrm{s}}=0.37, \mathrm{P}<\right.$ $0.01)$, BMI and VSR $\left(\mathrm{r}_{\mathrm{s}}=0.22, \mathrm{P}<0.01\right), \mathrm{PMI}$ and $\mathrm{VSR}\left(\mathrm{r}_{\mathrm{s}}=\right.$ $0.18, \mathrm{P}=0.02)$ and IMAC and VSR $\left(\mathrm{r}_{\mathrm{s}}=0.30, \mathrm{P}<0.01\right)$.

Tables 1-4 compare backgrounds, EGFR-TKI regimen, treatment efficacy, and pretreatment NLR between high and low BMI, PMI, IMAC and VSR, respectively. Low BMI group included more patients with $\geq 3$ metastatic sites than high BMI group. In contrast, extra-pulmonary metastasis was not significantly different between high and low BMI groups (Table $1)$. Neither number of metastatic sites $(<3$ vs. $\geq 3)$ nor extrapulmonary metastases was significantly different between high and low PMI, IMAC and VSR groups (Tables 2-4).

Comparisons of OS and PFS according to BMI, PMI, IMAC and VSR are presented in Figures 2 and 3, respectively. The OS (median 26.0 vs. 32.3 months, $\mathrm{P}=0.02$ ) (Fig. 2a) and PFS (median 9.1 vs. 14.8 months, $\mathrm{P}=0.03$ ) (Fig. 3a) of underweight patients $(\mathrm{BMI}<18.5)$ were shorter than those of patients with $\mathrm{BMI} \geq 18.5$. In contrast, there was no significant difference in OS and PFS according to PMI, IMAC and 
Table 1. Baseline Characteristics According to Body Mass Index

\begin{tabular}{|c|c|c|c|}
\hline & \multicolumn{2}{|c|}{ BMI } & \multirow{2}{*}{$\mathbf{P}$} \\
\hline & $\geq 18.5$ & $<18.5$ & \\
\hline $\mathrm{N}$ & 134 & 33 & \\
\hline \multicolumn{4}{|l|}{$\operatorname{Sex}(N)$} \\
\hline Male/female & $50 / 84$ & $13 / 20$ & $0.84^{\mathrm{a}}$ \\
\hline$<75 / \geq 75$ years $(N)$ & $82 / 52$ & $18 / 15$ & $0.55^{\mathrm{a}}$ \\
\hline \multicolumn{4}{|l|}{ Smoking status } \\
\hline NS/Ex, CS & $69 / 65$ & $16 / 17$ & $0.85^{\mathrm{a}}$ \\
\hline \multicolumn{4}{|l|}{ EGFR mutation } \\
\hline \multicolumn{4}{|l|}{ Extra-pulmonary metastases } \\
\hline Yes/no & $72 / 62$ & $20 / 13$ & $0.56^{\mathrm{a}}$ \\
\hline \multicolumn{4}{|l|}{ Metastatic sites } \\
\hline$<3 / \geq 3$ & $68 / 66$ & $8 / 25$ & $<0.01^{\mathrm{a}}$ \\
\hline \multicolumn{4}{|l|}{ BMI } \\
\hline Median (IQR) & $23.2(21.1-24.8)$ & $17.7(16.4-18.1)$ & $<0.01^{\mathrm{b}}$ \\
\hline \multicolumn{4}{|l|}{ Treatment $(\mathrm{N})$} \\
\hline \multicolumn{4}{|l|}{ Regimen } \\
\hline Gefitinib/erlotinib/afatinib & $15 / 31 / 88$ & $2 / 11 / 20$ & $0.44^{\mathrm{a}}$ \\
\hline \multicolumn{4}{|l|}{ Line } \\
\hline \multicolumn{4}{|l|}{ TKI efficacy } \\
\hline $\mathrm{CR} / \mathrm{PR} / \mathrm{SD} / \mathrm{PD} / \mathrm{NE}$ & $6 / 82 / 26 / 15 / 5$ & $1 / 16 / 5 / 5 / 6$ & \\
\hline ORR (\%) $(95 \% \mathrm{CI})$ & $65.7(57.0-73.7)$ & $51.5(33.5-69.2)$ & $0.16^{\mathrm{a}}$ \\
\hline $\operatorname{DCR}(\%)(95 \% \mathrm{CI})$ & $85.1(77.9-90.6)$ & $66.7(48.2-82.0)$ & $0.02^{\mathrm{a}}$ \\
\hline \multicolumn{4}{|l|}{ Laboratory data } \\
\hline \multicolumn{4}{|l|}{ NLR } \\
\hline Median (IQR) & $2.51(1.78-4.27)$ & $2.98(2.20-3.98)$ & $0.23^{\mathrm{b}}$ \\
\hline$\leq 5 />5(\mathrm{~N})$ & $112 / 22$ & $28 / 5$ & $1.00^{\mathrm{a}}$ \\
\hline
\end{tabular}

aFisher's exact test. 'bMann-Whitney U test. BMI: body mass index; CI: confidence interval; CR: complete response; CS: current smoker; DCR: disease control rate; ECOG-PS: Eastern Cooperative Oncology Group performance status; EGFR: epidermal growth factor receptor; Ex: ex-smoker; ICI: immune-checkpoint inhibitors; IQR: interquartile range; NE: not evaluated; NLR: neutrophil-to-lymphocyte ratio; NS: non-smoker; ORR: overall response rate; PD: progressive disease; PR: partial response; SD: stable disease; TKI: tyrosine kinase inhibitor.

VSR (Figs. 2 and 3). Adjusted by age, NLR, ECOG-PS, EGFR mutation type, regimen line and extra-pulmonary metastases, multivariate Cox proportional hazard analyses detected only $\mathrm{BMI}<18.5$ as an unfavorable prognostic factor of shorter OS
(HR 1.70, 95\% CI $1.03-2.81, \mathrm{P}=0.04)$ and PFS (HR 1.72, $95 \%$ CI $1.11-2.67, \mathrm{P}=0.02$ ) (Table 5). However, when extra-pulmonary metastases was replaced by three or more than three metastatic sites as an explanatory variable, multivariate 
Table 2. Baseline Characteristics According to Psoas Muscle Index

\begin{tabular}{llll}
\hline & \multicolumn{2}{c}{ PMI } \\
\cline { 2 - 3 } & Low & High \\
\hline $\mathrm{N}$ & 102 & 65
\end{tabular}

Backgrounds

$\operatorname{Sex}(\mathrm{N})$
Male/female
$43 / 59$
20/45
$0.15^{\mathrm{a}}$

Age (years)

Median (IQR)

$<75 / \geq 75$ years $(\mathrm{N})$

$74(66-79)$

$58 / 44$

Smoking status

NS/Ex, CS

$49 / 53$

$45 / 57$

$71 / 23 / 8$

$60 / 42$

$0.27^{\mathrm{a}}$

Metastatic sites

$$
<3 / \geq 3
$$

$46 / 56$

$21.2(18.3-23.4)$

$3.53(2.91-4.45)$

Median (IQR)

Treatment (N)

Regimen

Gefitinib/erlotinib/afatinib

$65 / 28 / 9$

$43 / 14 / 8$

$0.59^{\mathrm{a}}$

Line

First/second or later

$74 / 28$

$0.73^{\mathrm{a}}$

Post-TKI treatment

$\begin{array}{ll}\text { Osimertinib } & 10 \\ \text { ICI therapy } & 6\end{array}$

10

6

14

8

$0.04^{\mathrm{a}}$

$0.16^{\mathrm{a}}$

TKI efficacy

$\begin{array}{ll}\mathrm{CR} / \mathrm{PR} / \mathrm{SD} / \mathrm{PD} / \mathrm{NE} & 4 / 55 / 19 / 14 / 10 \\ \text { ORR }(\%)(95 \% \mathrm{CI}) & 57.8(47.7-67.6) \\ \mathrm{DCR}(\%)(95 \% \mathrm{CI}) & 76.5(67.0-84.3)\end{array}$

Laboratory data

NLR

$$
\begin{aligned}
& \text { Median (IQR) } \\
& \leq 5 />5(\mathrm{~N})
\end{aligned}
$$

$\begin{array}{ll}3 / 43 / 12 / 6 / 1 & \\ 70.8(58.2-81.4) & 0.10^{\mathrm{a}} \\ 89.2(79.1-95.6) & 0.04^{\mathrm{a}}\end{array}$

$3 / 43 / 12 / 6 / 1$

aFisher's exact test. 'bMann-Whitney U test. BMI: body mass index; CI: confidence interval; CR: complete response; CS: current smoker; DCR: disease control rate; ECOG-PS: Eastern Cooperative Oncology Group performance status; EGFR: epidermal growth factor receptor; Ex: exsmoker; ICl: immune-checkpoint inhibitors; IQR: interquartile range; NE: not evaluated; NLR: neutrophil-to-lymphocyte ratio; NS: non-smoker; ORR: overall response rate; PD: progressive disease; PMI: psoas muscle index; PR: partial response; SD: stable disease; TKI: tyrosine kinase inhibitor. 
Table 3. Baseline Characteristics According to Intramuscular Adipose Tissue Content

\begin{tabular}{llll}
\hline & \multicolumn{2}{c}{ IMAC } \\
\cline { 2 - 3 } & Low & High \\
\hline $\mathrm{N}$ & 148 & 19
\end{tabular}

Backgrounds

$\operatorname{Sex}(\mathrm{N})$
Male/female
$91 / 57$
$13 / 6$
$0.62^{\mathrm{a}}$

Age (years)

Median (IQR)

$72(64-77)$

$76(69.5-81)$

$0.04^{\mathrm{b}}$

$<75 / \geq 75$ years $(\mathrm{N})$

$91 / 57$

$9 / 10$

$0.32^{\mathrm{a}}$

Smoking status

NS/Ex, CS

$77 / 71$

$8 / 11$

$0.47^{\mathrm{a}}$

EGFR mutation

Ex19del/others

$70 / 78$

$10 / 9$

$0.81^{\mathrm{a}}$

ECOG-PS

$0-1 / 2 / 3-4$

Extra-pulmonary metastases

Yes/no

$114 / 24 / 10$

$11 / 7 / 1$

$0.10^{\mathrm{a}}$

$12 / 7$

$0.63^{\mathrm{a}}$
Metastatic sites

$$
<3 / \geq 3
$$

$70 / 78$

$6 / 13$

$0.23^{\mathrm{a}}$

BMI

Median (IQR)

$20.1(19.1-24.4)$

$22.3(20.1-24.4)$

$0.68^{\mathrm{a}}$

IMAC

Median (IQR)

$-0.52(-0.63,-0.43)$

$-0.16(-0.23,-0.10)$

Treatment $(\mathrm{N})$

Regimen

Gefitinib/erlotinib/afatinib

$97 / 35 / 16$

$11 / 7 / 1$

$0.45^{\mathrm{a}}$

Line

First/second or later

$106 / 42$

$13 / 6$

$0.79^{\mathrm{a}}$

Post-TKI treatment

$\begin{array}{lll}\text { Osimertinib } & 23 \\ \text { ICI therapy } & 1\end{array}$

23

14

TKI efficacy

$\begin{array}{ll}\mathrm{CR} / \mathrm{PR} / \mathrm{SD} / \mathrm{PD} / \mathrm{NE} & 33 / 81 / 24 / 8 / 2 \\ \text { ORR }(\%)(95 \% \mathrm{CI}) & 77.0(69.4-83.5) \\ \text { DCR }(\%)(95 \% \mathrm{CI}) & 93.2(87.9-96.7)\end{array}$

Laboratory data

NLR

$$
\begin{aligned}
& \text { Median (IQR) } \\
& \leq 5 />5(\mathrm{~N})
\end{aligned}
$$

1

0

$3 / 8 / 7 / 1$

$\begin{array}{ll}57.9(33.5-79.7) & 0.09^{\mathrm{a}} \\ 94.7(74.0-99.9) & 1.00^{\mathrm{a}}\end{array}$

$0.32^{\mathrm{a}}$

$0.37^{\mathrm{a}}$

$1.00^{\mathrm{a}}$

aFisher's exact test. 'bMann-Whitney U test. BMI: body mass index; Cl: confidence interval; CR: complete response; CS: current smoker; DCR: disease control rate; ECOG-PS: Eastern Cooperative Oncology Group performance status; EGFR: epidermal growth factor receptor; Ex: ex-smoker; ICl: immune-checkpoint inhibitors; IMAC: intramuscular adipose tissue content; IQR: interquartile range; NE: not evaluated; NLR: neutrophil-tolymphocyte ratio; NS: non-smoker; ORR: overall response rate; PD: progressive disease; PR: partial response; SD: stable disease; TKI: tyrosine kinase inhibitor. 
Table 4. Baseline Characteristics According to Visceral-to-Subcutaneous Adipose Tissue Area Ratio

\begin{tabular}{|c|c|c|c|}
\hline & & & D \\
\hline & Low & High & $\mathbf{P}$ \\
\hline $\mathrm{N}$ & 128 & 39 & \\
\hline
\end{tabular}

Backgrounds

$\operatorname{Sex}(\mathrm{N})$
Male/female
$44 / 84$
$19 / 20$
$0.13^{\mathrm{a}}$

Age (years)

$\begin{array}{llll}\text { Median }(\mathrm{IQR}) & 71(64-76) & 77(70.5-80.5) & <0.01^{\mathrm{b}} \\ <75 / \geq 75 \text { years }(\mathrm{N}) & 83 / 45 & 17 / 22 & 0.02^{\mathrm{a}}\end{array}$

Smoking status

NS/Ex, CS

$65 / 63$

20/19

$1.00^{\mathrm{a}}$

EGFR mutation

Ex19del/others

$62 / 66$

$18 / 21$

$0.86^{\mathrm{a}}$

ECOG-PS

$0-1 / 2 / 3-4$

$97 / 23 / 8$

$28 / 8 / 3$

$0.81^{\mathrm{a}}$

Extra-pulmonary metastases

Yes/no

$69 / 59$

$54 / 74$

$21.6(19.1-24.1)$

$0.41(0.23-0.74)$

Median (IQR)

Treatment $(\mathrm{N})$

Regimen

Gefitinib/erlotinib/afatinib

$82 / 31 / 15$

$26 / 11 / 2$

$0.54^{\mathrm{a}}$

Line

First/second or later

$91 / 37$

$28 / 11$

$1.00^{\mathrm{a}}$

Post-TKI treatment

$\begin{array}{ll}\text { Osimertinib } & 20 \\ \text { ICI therapy } & 12\end{array}$

12

TKI efficacy

$\begin{array}{ll}\mathrm{CR} / \mathrm{PR} / \mathrm{SD} / \mathrm{PD} / \mathrm{NE} & 4 / 79 / 23 / 15 / 7 \\ \text { ORR (\%) }(95 \% \mathrm{CI}) & 64.8(55.9-73.1) \\ \mathrm{DCR}(\%)(95 \% \mathrm{CI}) & 82.8(75.1-88.9)\end{array}$

Laboratory data

NLR

$$
\begin{aligned}
& \text { Median (IQR) } \\
& \leq 5 />5(\mathrm{~N})
\end{aligned}
$$

4

2

$0.60^{\mathrm{a}}$

$0.52^{\mathrm{a}}$

$3 / 19 / 8 / 5 / 4$

$56.4(39.6-72.2) \quad 0.35^{\mathrm{a}}$

$76.9(60.7-88.9) \quad 0.48^{\mathrm{a}}$

aFisher's exact test. 'bMann-Whitney U test. BMI: body mass index; Cl: confidence interval; CR: complete response; CS: current smoker; DCR: disease control rate; ECOG-PS: Eastern Cooperative Oncology Group performance status; EGFR: epidermal growth factor receptor; Ex: ex-smoker; ICl: immune-checkpoint inhibitors; IQR: interquartile range; NE: not evaluated; NLR: neutrophil-to-lymphocyte ratio; NS: non-smoker; ORR: overall response rate; PD: progressive disease; PR: partial response; SD: stable disease; TKI: tyrosine kinase inhibitor; VSR: visceral-to-subcutaneous adipose tissue area ratio. 

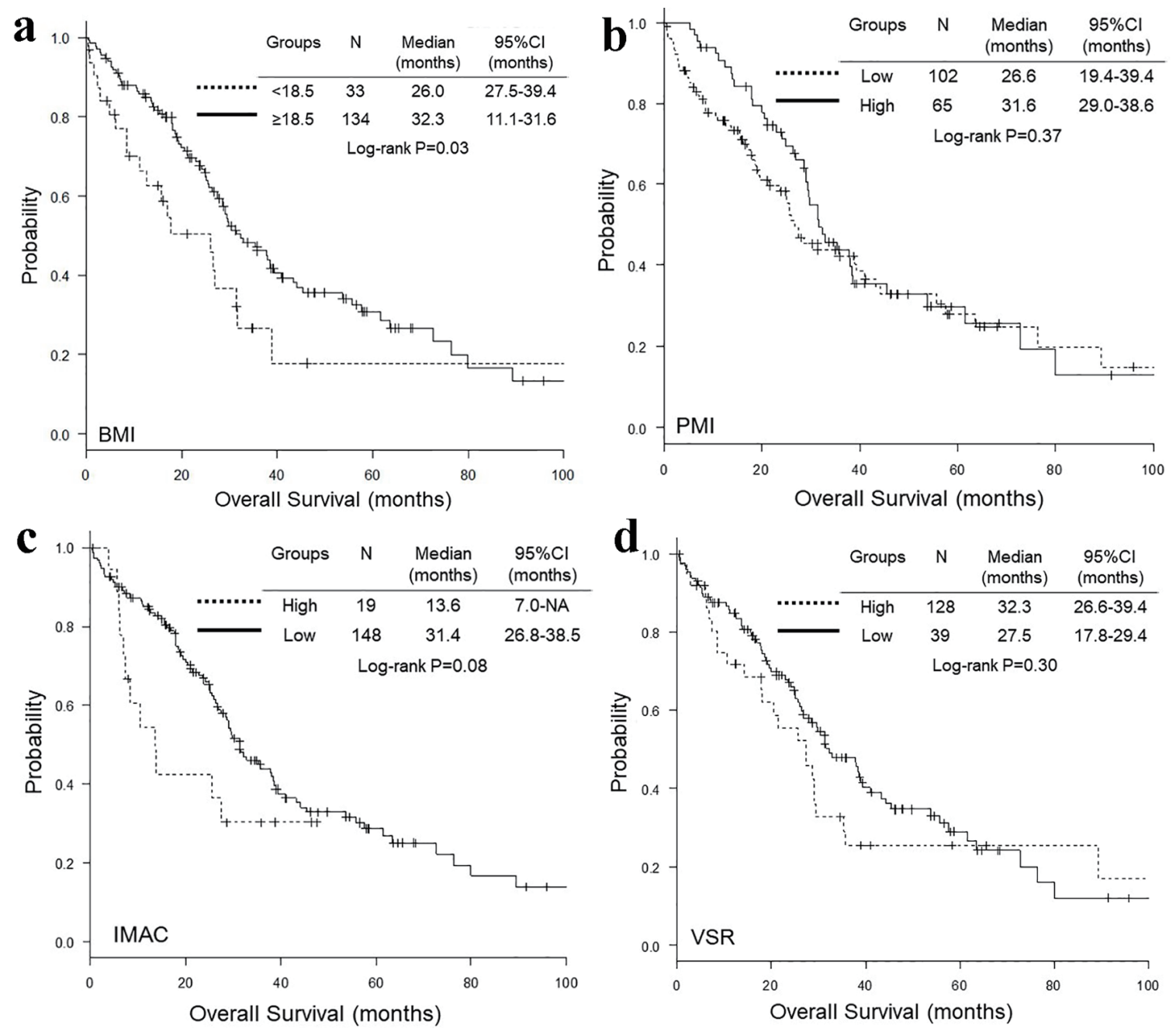

Figure 2. Kaplan-Meier curves of overall survival according to BMI (a), PMI (b), IMAC (c) and VSR (d). BMI: body mass index; PMI: psoas muscle index; IMAC: intramuscular adipose tissue content; VSR: visceral-to-subcutaneous adipose tissue area ratio.

analyses did not detect BMI as independent prognostic factors of OS (HR 1.48, 95\% CI $0.89-2.46, \mathrm{P}=0.13)$ and PFS (HR $1.36,95 \%$ CI $0.87-2.13, \mathrm{P}=0.18$ ) (Table 6).

\section{Discussion}

Our study investigated whether pretreatment underweight, sarcopenia and visceral adiposity were prognostic markers of survival benefit of EGFR-TKIs for patients with mutant EGFR.

The most important finding was that underweight is associated with shorter PFS and OS of EGFR-TKIs. Underweight $\left(\mathrm{BMI}<18.5 \mathrm{~kg} / \mathrm{m}^{2}\right)$ has been shown as a worse prognostic factor not only in operable patients with early stage of lung cancer [20-22], but also in patients with advanced lung cancer [2, 23]. In contrast, regarding patients with mutant EGFR, BMI has been controversial as a prognostic factor [24-27]. Two Japanese studies of 138 patients treated with gefitinib [24] and of 47 patients with acquired T790M-positive mutation who had been treated with osimertinib after prior EGFR-TKI [25] failed to show any significant differences in response and PFS among underweight, normal weight and overweight patients, and between patients with $\mathrm{BMI}<21.5$ and those with $\mathrm{BMI} \geq 21.5$, respectively. Oppositely, in a Korean study of 95 patients, patients with BMI $\leq 20.8$ had a longer PFS than those with BMI > 20.8 [27]. In another Korean study of 630 patients, multi-variable analysis detected BMI $<18.5$ as an independent worse prognostic factor for PFS and OS [26]. In our study, the frequency of three or more metastatic sites was significantly higher in underweight patients groups. In our multivariate analyses, BMI was different as independent prognostic factors of OS and PFS, whether extra-pulmonary metastases or number of metastatic sites $(<3$ or $\geq 3$ ) was used as an explanatory variable. Our multivariate analyses detected number of metastatic sites $(<3$ or $\geq 3)$, but not BMI, as a significant prognostic factor. Therefore, our data suggested that BMI may be a surrogate marker of tumor burden. In some patients, decreased body weight might be a result of severer and longer symptoms due to advanced metastatic diseases. Thus, it requires further investigations whether BMI is really a prognostic marker of EGFR-TKIs. 

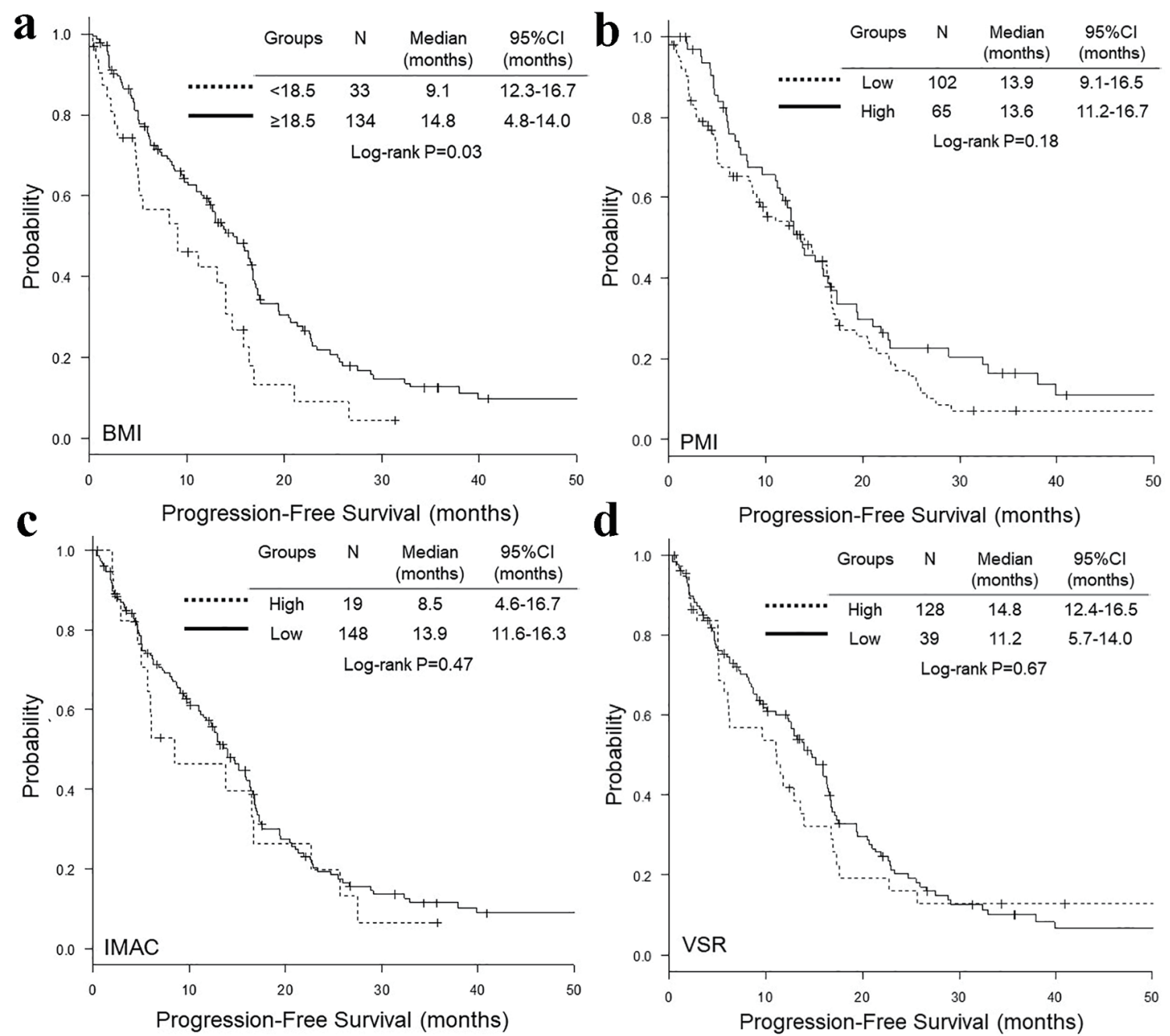

Figure 3. Kaplan-Meier curves of progression-free survival according to BMI (a), PMI (b), IMAC (c) and VSR (d). BMI: body mass index; PMI: psoas muscle index; IMAC: intramuscular adipose tissue content; VSR: visceral-to-subcutaneous adipose tissue area ratio.

The second important finding was that neither sarcopenia nor visceral obesity was a significant prognostic factor for patients treated with EGFR-TKIs. Our study was the second study that had investigated the association of sarcopenia with outcomes of EGFR-TKIs. Both the previous Italian [13] and our studies failed to show sarcopenia as a significant prognostic factor of EGFR-TKI therapy. Thus, irrespective of pretreatment sarcopenia, EGFR-TKI should be considered for patients with mutant EGFR. On the other hand, our study was the first study evaluating visceral obesity as a prognostic marker of EGFR-TKI therapy. Visceral obesity with low BMI has been suggested to be at high risk for development of lung cancer [28]. However, it has remained unknown whether visceral obesity is associated with worse outcomes of chemotherapy in NSCLC patients. As a result, our study failed to demonstrate the association of visceral obesity with poor prognosis of EGFR-TKI therapy.

Our study included some limitations. First, there might be bias and low validity in our results due to our study design, retro- spective and single-institutional, and small sample size. Second, first- and second-generation EGFR-TKI is becoming behind the times. Our study did not reflect the times of the third-generation EGFR-TKI, osimertinib. Further investigations may be warranted for patients with EGFR mutant treated with osimertinib.

\section{Conclusion}

Pretreatment underweight was a significant prognostic factor of poor PFS and OS of EGFR-TKI therapy. However, neither pretreatment sarcopenia nor visceral obesity was associated with prognosis of EGFR-TKI. Underweight may be a surrogate for advanced disease burden.

\section{Acknowledgments}

We are grateful to Kazunori Moriizumi, Saori Ikebe, Hideyasu 
Table 5. Adjusted Hazard Ratios of Markers of Sarcopenia and Visceral Obesity by Age, Neutrophil to Lymphocyte Ratio, ECOG-PS, EGFR Mutation Type, Regimen Line and Extra-Pulmonary Metastases

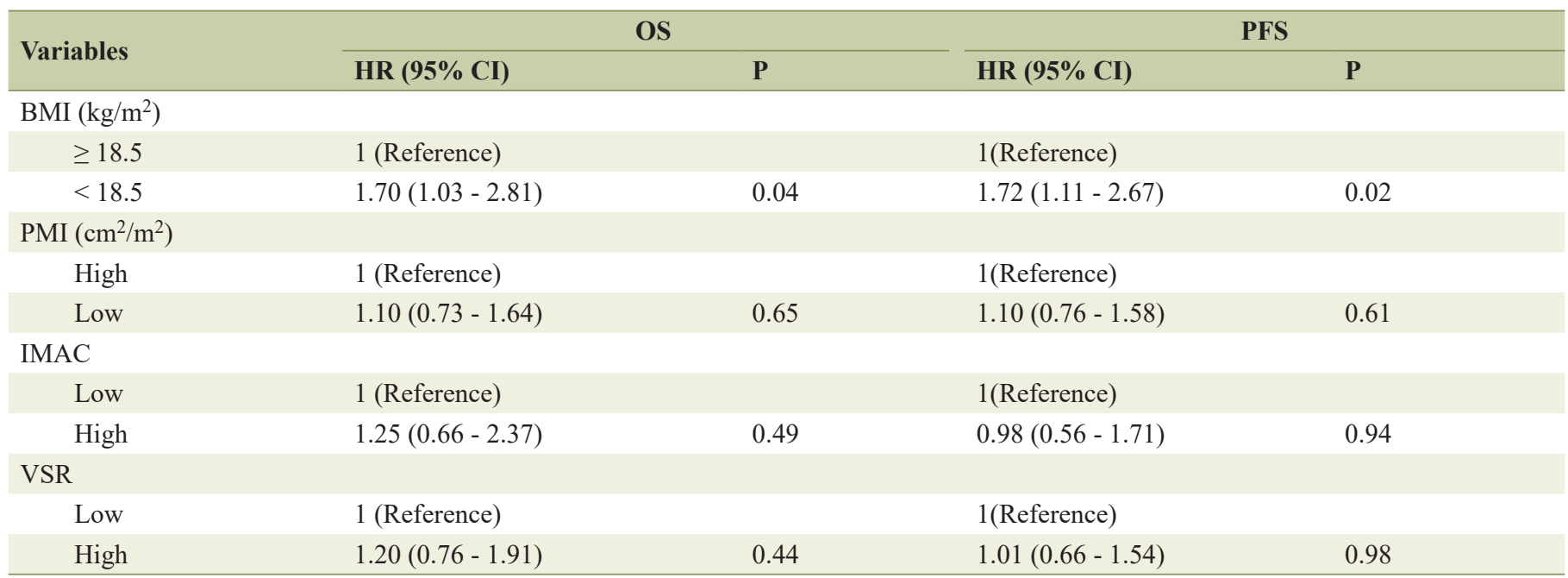

Multivariate adjustment for age (<75 vs. $\geq 75$ years), neutrophil to lymphocyte ratio (<5 vs. $\geq 5$ ), ECOG-PS (0 - 1 vs. $2-4$ ), EGFR mutation type (exon 19 deletion vs. others), regimen line (first-line vs. second or later line) and extra-pulmonary metastases (yes vs. no). BMI: body mass index; Cl: confidence interval; ECOG-PS: Eastern Cooperative Oncology Group performance status; EGFR: epidermal growth factor receptor; HR: hazard ratio; IMAC: intramuscular adipose tissue content; OS: overall survival; PFS: progression-free survival; PMI: psoas muscle index; VFA: visceral fat area; VSR: visceral-to-subcutaneous adipose tissue area ratio.

Table 6. Multivariate Cox Proportional Hazard Analyses, When Extra-Pulmonary Metastases Was Replaced by Numbers of Metastatic Sites as an Explanatory Variable

\begin{tabular}{|c|c|c|c|c|}
\hline \multirow{2}{*}{ Variables } & \multicolumn{2}{|c|}{ OS } & \multicolumn{2}{|c|}{ PFS } \\
\hline & HR $(95 \%$ CI) & $\mathbf{P}$ & HR $(95 \%$ CI) & $\mathbf{P}$ \\
\hline \multicolumn{5}{|l|}{ Age } \\
\hline$\geq 75$ years & $1.08(0.72-1.64)$ & 0.71 & $0.86(0.59-1.24)$ & 0.42 \\
\hline \multicolumn{5}{|l|}{ NLR } \\
\hline$<5$ & 1 (Reference) & & 1(Reference) & \\
\hline \multicolumn{5}{|l|}{ ECOG-PS } \\
\hline $0-1$ & 1 (Reference) & & 1(Reference) & \\
\hline $2-4$ & $2.86(1.80-4.54)$ & $<0.01$ & $2.09(1.39-3.13)$ & $<0.01$ \\
\hline \multicolumn{5}{|l|}{ EGFR mutation } \\
\hline Exon 19 del & 1 (Reference) & & 1 (Reference) & \\
\hline Second or later & $1.72(1.12-2.65)$ & 0.01 & $1.46(1.00-2.12)$ & 0.049 \\
\hline \multicolumn{5}{|l|}{ Metastatic sites } \\
\hline$<3$ & 1 (Reference) & & 1 (Reference) & \\
\hline$\geq 3$ & $1.96(1.28-3.00)$ & $<0.01$ & $2.11(1.46-3.05)$ & $<0.01$ \\
\hline \multicolumn{5}{|l|}{ BMI $\left(\mathrm{kg} / \mathrm{m}^{2}\right)$} \\
\hline$\geq 18.5$ & 1 (Reference) & & 1(Reference) & \\
\hline$<18.5$ & $1.48(0.89-2.46)$ & 0.13 & $1.36(0.87-2.13)$ & 0.18 \\
\hline
\end{tabular}

BMI: body mass index; Cl: confidence interval; ECOG-PS: Eastern Cooperative Oncology Group performance status; EGFR: epidermal growth factor receptor; HR: hazard ratio; NLR: neutrophil-to-lymphocyte ratio; OS: overall survival; PFS: progression-free survival. 
Okada and Kensuke Kanaoka at the Department of Respiratory Medicine, Osaka Police Hospital, and Tsunehiro Tanaka and Kazuki Hashimoto at the Department of Respiratory Medicine, Daini Osaka Police Hospital, for their medical records, diagnosis, treatment and care of their patients.

\section{Financial Disclosure}

None to declare.

\section{Conflict of Interest}

The authors declare that they have no conflict of interests.

\section{Informed Consent}

The Osaka Police Hospital Ethics Committee approved waiver of the written informed consents in view of the retrospective and anonymous characteristics.

\section{Author Contributions}

Seigo Minami designed, performed the statistical analysis of the data, and drafted the manuscript. All authors were involved in the conceptual design, review of the draft, and approved the final manuscript. Komuta Kiyoshi supervised all aspects of the study.

\section{References}

1. Mandrekar SJ, Schild SE, Hillman SL, Allen KL, Marks RS, Mailliard JA, Krook JE, et al. A prognostic model for advanced stage nonsmall cell lung cancer. Pooled analysis of North Central Cancer Treatment Group trials. Cancer. 2006;107(4):781-792.

2. Shepshelovich D, Xu W, Lu L, Fares A, Yang P, Christiani D, Zhang J, et al. Body Mass Index (BMI), BMI change, and overall survival in patients with SCLC and NSCLC: a pooled analysis of the international lung cancer consortium. J Thorac Oncol. 2019;14(9):1594-1607.

3. Strulov Shachar S, Williams GR. The Obesity Paradox in Cancer-Moving Beyond BMI. Cancer Epidemiol Biomarkers Prev. 2017;26(1):13-16.

4. Ballian N, Lubner MG, Munoz A, Harms BA, Heise CP, Foley EF, Kennedy GD. Visceral obesity is associated with outcomes of total mesorectal excision for rectal adenocarcinoma. J Surg Oncol. 2012;105(4):365-370.

5. Guiu B, Petit JM, Bonnetain F, Ladoire S, Guiu S, Cercueil JP, Krause D, et al. Visceral fat area is an independent predictive biomarker of outcome after first-line bevacizumab-based treatment in metastatic colorectal cancer. Gut. 2010;59(3):341-347.

6. Bian X, Dai H, Feng J, Ji H, Fang Y, Jiang N, Li W. Prog- nostic values of abdominal body compositions on survival in advanced pancreatic cancer. Medicine (Baltimore). 2018;97(22):e10988.

7. Clark W, Siegel EM, Chen YA, Zhao X, Parsons CM, Hernandez JM, Weber J, et al. Quantitative measures of visceral adiposity and body mass index in predicting rectal cancer outcomes after neoadjuvant chemoradiation. J Am Coll Surg. 2013;216(6):1070-1081.

8. Lee HW, Jeong BC, Seo SI, Jeon SS, Lee HM, Choi HY, Jeon HG. Prognostic significance of visceral obesity in patients with advanced renal cell carcinoma undergoing nephrectomy. Int J Urol. 2015;22(5):455-461.

9. Okamura A, Watanabe M, Yamashita K, Yuda M, Hayami M, Imamura Y, Mine S. Implication of visceral obesity in patients with esophageal squamous cell carcinoma. Langenbecks Arch Surg. 2018;403(2):245-253.

10. Slaughter KN, Thai T, Penaroza S, Benbrook DM, Thavathiru E, Ding K, Nelson T, et al. Measurements of adiposity as clinical biomarkers for first-line bevacizumab-based chemotherapy in epithelial ovarian cancer. Gynecol Oncol. 2014;133(1):11-15.

11. Cruz-Jentoft AJ, Bahat G, Bauer J, Boirie Y, Bruyere O, Cederholm T, Cooper C, et al. Sarcopenia: revised European consensus on definition and diagnosis. Age Ageing. 2019;48(1):16-31.

12. Shachar SS, Williams GR, Muss HB, Nishijima TF. Prognostic value of sarcopenia in adults with solid tumours: A meta-analysis and systematic review. Eur J Cancer. 2016;57:58-67.

13. Rossi S, Di Noia V, Tonetti L, Strippoli A, Basso M, Schinzari G, Cassano A, et al. Does sarcopenia affect outcome in patients with non-small-cell lung cancer harboring EGFR mutations? Future Oncol. 2018;14(10):919926.

14. Eisenhauer EA, Therasse P, Bogaerts J, Schwartz LH, Sargent D, Ford R, Dancey J, et al. New response evaluation criteria in solid tumours: revised RECIST guideline (version 1.1). Eur J Cancer. 2009;45(2):228-247.

15. Hamaguchi Y, Kaido T, Okumura S, Kobayashi A, Hammad A, Tamai Y, Inagaki N, et al. Proposal for new diagnostic criteria for low skeletal muscle mass based on computed tomography imaging in Asian adults. Nutrition. 2016;32(11-12):1200-1205.

16. Kitajima Y, Hyogo H, Sumida Y, Eguchi Y, Ono N, Kuwashiro T, Tanaka K, et al. Severity of non-alcoholic steatohepatitis is associated with substitution of adipose tissue in skeletal muscle. J Gastroenterol Hepatol. 2013;28(9):1507-1514

17. Hamaguchi Y, Kaido T, Okumura S, Kobayashi A, Shirai $\mathrm{H}$, Yagi S, Kamo N, et al. Impact of skeletal muscle mass index, intramuscular adipose tissue content, and visceral to subcutaneous adipose tissue area ratio on early mortality of living donor liver transplantation. Transplantation. 2017;101(3):565-574.

18. Fujiwara N, Nakagawa H, Kudo Y, Tateishi R, Taguri M, Watadani T, Nakagomi R, et al. Sarcopenia, intramuscular fat deposition, and visceral adiposity independently predict the outcomes of hepatocellular carcinoma. J Hepatol. 2015;63(1):131-140. 
19. Kanda Y. Investigation of the freely available easy-touse software 'EZR' for medical statistics. Bone Marrow Transplant. 2013;48(3):452-458.

20. Nagata M, Ito H, Matsuzaki T, Furumoto H, Isaka T, Nishii $\mathrm{T}$, Yokose $\mathrm{T}$, et al. Body mass index, C-reactive protein and survival in smokers undergoing lobectomy for lung cancerdagger. Eur J Cardiothorac Surg. 2017;51(6):11641170 .

21. Takada K, Shimokawa M, Akamine T, Ono Y, Haro A, Osoegawa A, Tagawa T, et al. Association of low body mass index with poor clinical outcomes after resection of non-small cell lung cancer. Anticancer Res. 2019;39(4):1987-1996.

22. Tomita M, Ayabe T, Nakamura K. Low body mass index is an independent predictive factor after surgical resection in patients with non-small cell lung cancer. Asian Pac J Cancer Prev. 2017;18(12):3353-3356.

23. Masel EK, Berghoff AS, Fureder LM, Heicappell P, Schlieter F, Widhalm G, Gatterbauer B, et al. Decreased body mass index is associated with impaired survival in lung cancer patients with brain metastases: A retrospective analysis of 624 patients. Eur J Cancer Care (Engl). 2017;26(6):e12707.

24. Imai H, Kuwako T, Kaira K, Masuda T, Miura Y, Seki $\mathrm{K}$, Sakurai R, et al. Evaluation of gefitinib efficacy ac- cording to body mass index, body surface area, and body weight in patients with EGFR-mutated advanced nonsmall cell lung cancer. Cancer Chemother Pharmacol. 2017;79(3):497-505.

25. Ono T, Igawa S, Ozawa T, Kasajima M, Ishihara M, Hiyoshi Y, Kusuhara S, et al. Evaluation of osimertinib efficacy according to body surface area and body mass index in patients with non-small cell lung cancer harboring an EGFR mutation: A prospective observational study. Thorac Cancer. 2019;10(4):880-889.

26. Park S, Park S, Lee SH, Suh B, Keam B, Kim TM, Kim DW, et al. Nutritional status in the era of target therapy: poor nutrition is a prognostic factor in non-small cell lung cancer with activating epidermal growth factor receptor mutations. Korean J Intern Med. 2016;31(6):1140-1149.

27. Sun H, Sun X, Zhai X, Guo J, Liu Y, Ying J, Wang Z. Body mass index and exon 19 mutation as factors predicting the therapeutic efficacy of gefitinib in patients with epidermal growth factor receptor mutation-positive nonsmall cell lung cancer. Thorac Cancer. 2016;7(1):61-65.

28. Yu D, Zheng W, Johansson M, Lan Q, Park Y, White E, Matthews CE, et al. Overall and central obesity and risk of lung cancer: a pooled analysis. J Natl Cancer Inst. 2018;110(8):831-842. 